\section{EMBRYRIDDLE}

Aeronautical University

SCHOLARLY COMMONS
Journal of Aviation/Aerospace Education \& Research

Volume 12

Number 1 JAAER Fall 2002

Article 5

Fall 2002

\title{
Military Versus Civilian Air Cargo Training for Hazardous Material
}

Bruce A. Rothwell

Wayne Harsha

Theodore Clever

Follow this and additional works at: https://commons.erau.edu/jaaer

\section{Scholarly Commons Citation}

Rothwell, B. A., Harsha, W., \& Clever, T. (2002). Military Versus Civilian Air Cargo Training for Hazardous Material. Journal of Aviation/Aerospace Education \& Research, 12(1). https://doi.org/10.15394/ jaaer.2002.1591

This Article is brought to you for free and open access by the Journals at Scholarly Commons. It has been accepted for inclusion in Journal of Aviation/Aerospace Education \& Research by an authorized administrator of Scholarly Commons. For more information, please contact commons@erau.edu. 


\title{
MILITARY VERSUS CIVILIAN AIR CARGO TRAINING FOR HAZARDOUS MATERIAL
}

\author{
Bruce A. Rothwell, Wayne Harsha, and Theodore Clever
}

\begin{abstract}
This paper addressed differences in the way air cargo handlers are trained in the military and civilian sectors. The paper reviewed the training process and determined which provided the most knowledgeable graduates. A brief review of the history of hazardous material accidents and incidents was presented to demonstrate the need for continuous and effective training. The main body of the paper addressed current directives and the current status of the industry. The researchers collected information from military and civilians who were actively involved in the air transportation of hazardous materials. These data were then used to test specific hypotheses concerning which group was more knowledgeable and therefore, received the best training. The researchers found that there were generally no differences in the overall knowledge level of the military and civilians tested concerning the air transport of hazardous materials. However, there were statistically significant differences found between the two different kinds of civilian carriers. There were also significant differences between military and civilian HAZMAT specialists when the individual's number of years of experience was taken into consideration.
\end{abstract}

\section{BACKGROUND}

Arguably the most publicized case of mishandling hazardous materials in the air transportation system stemmed from the 1996 crash involving Valujet flight 592 that killed 110 people (Mokhiber, 1999). The probable cause of the Valujet tragedy was a fire in the aircraft's class-D cargo compartment. Oxygen generators illegally placed on the aircraft as company material cargo started the fire. Although the generators caused the fire, there were several contributing factors that lead to the accident ("Chemical Oxygen," 1997). The generators were not properly prepared, packaged or labeled and the individuals directly involved had not received appropriate training in the handling of hazardous materials. The oxygen generators placed onboard the ill-fated Valujet aircraft were improperly identified as empty. The generators were also missing safety caps that were required to be installed anytime they were removed from the original aircraft. The generators provide emergency oxygen to airline passengers through a chemical reaction. However, the creation of the oxygen also produces heat in the 450 to 500 degrees
Fahrenheit (232 to 260 degrees centigrade) range ("Chemical Oxygen," 1997). In December of 1999, SabreTech was convicted on eight counts of mishandling hazardous materials resulting in the crash of Valujet flight 592 (Mokhiber, 1999).

Beckham (1999) discusses three different categories of accidents and places the 1996 Valujet crash in the group called systems accidents. These accidents are characterized as the result of confusion caused by our complex organizations and management of dangerous technologies. The Valujet crash was “... a web of events that ricocheted into catastrophe: mismarked crates, botched paperwork, poorly stored equipment, [and] pressure for profits... [all] of these things, individually insignificant and seemingly unrelated, conspired to bring the plane down" (Beckham, 1999 , p. 52). Basically, the daily management of complex organizations and technologies will inevitably result in failures that lead to accidents. Therefore, the more complex the solutions to an accident becomes, the more risk is added of an accident happening in the future (Beckham, 1999).

Although the Valujet crash may be the most recognized 
example of hazardous substances contributing to an aircraft accident or incident, it is by no means the only recent example. Also in 1996, a fire destroyed a Federal Express DC-10. Although the crew escaped, the fire destroyed a 95 million dollar aircraft and most of its $\mathbf{3 0 0}$ million dollar cargo ("After Smoke," 1998). Although the probable cause of the fire was listed as coming from an undetermined origin, investigators believe that flammable liquids inside a DNA synthesizer may have been the initial ignition source. Investigators found larger amounts of flammable fluids in the synthesizer than would normally appear if the unit had been correctly purged prior to air shipment. Because the synthesizer was required to be purged, it was shipped as (non-hazardous) general cargo. Investigators also felt the synthesizer contained less fluid after the fire than before it started. A search of the cargo for undeclared hazardous materials after the fire revealed seven aerosol cans, several other containers containing small amounts of hazardous substances, and over 90 pounds of marijuana. In addition, there were two containers of liquid with flash points of only 140 and 149 degrees Fahrenheit (60 and 65 degrees centigrade) ("After Smoke," 1998).

In 1991, after a flight landed in Greensboro, NC, a fire was found in the aircraft's cargo compartment. After the fire was extinguished, investigators searched through 28 pieces of passenger luggage and found undeclared hazardous materials. One passenger's bags produced a teargas device. Another passenger's luggage revealed two bottles of dichloromethane, which is volatile, toxic, and a narcotic. Other bags produced lamp oil and safety matches (Chipkevich, 1996).

Undeclared shipments of hazardous materials are less likely to be correctly packaged which further increases their risk (Rogers, 2001). Undeclared hazardous materials pose the greatest risk to those on and around aircraft (Warner \& Rooney, 1997). At the time of the Valujet crash, Valujet had a policy in place of refusing to ship all items identified as HAZMAT. Therefore, a significant potential problem is unidentified HAZMAT in the cargo compartments of passenger carrying airliners. Sometimes, these packages are shipped through the United States Postal Service ("Chemical Oxygen," 1997). Unless a package is identified as containing hazardous materials, carriers are not required to ask about the contents for air shipments within the United States ("After Smoke," 1998). "In fact, undeclared shipments appear to pose the greatest hazards in the world of dangerous goods" (Forsyth, 1998, p. 46).
Although the Valujet tragedy is on everyone's mind, it was a 1973 crash of a 707 in Boston that brought the need for air transportation of HAZMAT to the attention of the public and governing agencies alike. The Boston crash resulted from the 707 carrying nitric acid, which leaked, causing a fire. The fire caused smoke and the smoke prevented the crew from safely flying the aircraft. It was the Boston crash more than anything else that led to the creation of Annex 18, The Safe Transport of Dangerous goods by Air (and other detailed and technical instructions) in 1983 (Warner \& Rooney, 1997). Many of these technical instructions were created by the International Civil Aviation Organization (ICAO) and came from recommendations by the UN Committee of Experts on the Transport of Dangerous Goods and the International Atomic Energy Agency (Warner \& Rooney, 1997). In 1995, the United Nations published Recommendations on the Transport of Dangerous Goods which was created by the UN Committee of Experts on the Transport of Dangerous Goods to facilitate the safe transport of dangerous cargo.

In-flight fires are rare, but do occur. In 1988, an American Airlines flight also experienced a fire in its classD cargo compartment. Like the Valujet crash, the crew was unaware of the fire until it breached the cargo area and smoke entered the cabin. However, unlike the Valujet crash, the passengers and crew were all able to safely escape after landing. Improperly packaged unidentified hazardous materials started the fire in that incident ("Chemical Oxygen," 1997).

In addition to the notable HAZMAT instances above, there have been several other incidents. For example, solidstate rocket fuel cargo may have been a contributing factor in the crash of a South African Airways 747-200 that killed 159 in November of 1987. Although the crash was attributed to a fire of unknown ignition sources, at least one forensics investigator testified that the probable cause was solid-state rocket fuel carried on the aircraft ("Rocket Fuel," 2000). Also, investigators have found that an El Al Israel 747 that crashed into an apartment building in Amsterdam was carrying chemicals that can be used to make nerve gas (Forsyth, 1998).

HAZMAT incidents also occur during baggage loading operations. In October 1997, with passengers already onboard an American Airlines flight scheduled from Miami to Ecuador, baggage handlers dropped a package off a conveyor belt at plane-side. The package contained the corrosive pesticide Dowicide $A$ that burst and resulted in a 
noxious dust (Forsyth, 1997). The chemical Dowicide A is strong enough to eat through metals. A Miami Florida freight forwarder had tried to ship ten 50-pound bags of the pesticide as excess baggage on the flight. Most alarming about this incident was that the manufacture's warning labels were not visible to the airline because they had been covered up (Forsyth, 1997).

Obviously, companies that specialize in air cargo shipments must remain alert to the transportation of dangerous goods. Commercial passenger airlines also have a lot riding on the training of their people but corporate operators must remain vigilant concerning the transportation HAZMAT as well. As with the other forms of air transportation, the corporate operators can unknowingly carry HAZMAT too. For example, one corporate operator was penalized 375,000 dollars for unwittingly carrying a flammable substance within the cockpit of one of their flights (Trautveller, 2000).

HAZMAT violations can stem from many different things including the willful transportation of a known dangerous substance to the unintended transportation of everyday substances that are, none the less, hazardous. In addition to the hazardous materials that have gotten on board aircraft and caused problems, there are several notable instances where the HAZMAT was found and stopped before getting on the intended aircraft or was found at the completion of a safe shipment. For example, in 1999, Ocean Spray Cranberries was cited for trying to ship three five-gallon plastic containers of grapefruit oil without the proper identification. The grapefruit oil is categorized as a flammable liquid (Sobie, 1999). When a retail chain tried to air ship a gallon of paint in a fiberboard box, the FAA charged them with several different infractions. The company failed to "...comply with DOT Title 49 regulations for packaging, labeling, marking, classing, describing and documenting the product, as well as for [failing to ensure] that its employees were adequately trained and that emergency response information was available" (Thomas, 2001, p. 32). There is even an example of a passenger with fireworks in a carry-on bag being stopped from boarding an aircraft in St. Louis (Martin, 1999).

The FAA can impose a penalty even if the carrier refuses to ship improperly marked dangerous cargo. For example, a company tried unsuccessfully to ship $\mathbf{5 2 5}$ gas cigarette lighters and received a proposed 165,000 dollar fine (Sobie, 1999). Not knowing the law and attempting to ship hazardous materials is not a valid defense against FAA citations and penalties (Thomas, 2001). However, more significant than a penalty would be the terrible knowledge that one had contributed to the destruction of an aircraft and loss of lives that accompanied a HAZMAT induced accident.

Since the Valujet crash, the FAA increased its HAZMAT workforce by about 500 percent. The larger manpower pool also increased the number of penalties enforced against companies for noncompliance with HAZMAT requirements (Martin, 1999; Forsyth, 1998). In 1998, the FAA issued more than 19 million dollars in fines for alleged hazardous material violations. The 19 million dollar figure was up more than 750 percent since 1996, the year of the Valujet crash. Further, the number of air safety incidents that involved hazardous substances totaled 1,369 in 1999 (Sobie, 1999). In 1987, 163 hazardous material releases were reported to the DOT Hazardous Materials Information System (HMIS). Ten years later the number rose to 1,015 incidents. In 1990, 21 percent of the releases were for undeclared hazardous shipments. In 1997, the percentage of undeclared hazardous shipments was 35 percent of all shipments involved in an incident ("After Smoke," 1998).

The carriers receive a premium for each hazardous shipment. The premium can be as much as 150 percent of the price charged for general cargo (Gethin, 1996). Further, carriers make more money when they can fly with a full load. Therefore, when there is available space, commercial carriers have to make effective use of it to remain competitive.

The military has not been immune from hazardous material incidents on their aircraft. Voge and Tolan (1993) conducted a study that looked at a decade's (January 1980 to January 1990) worth of military incidents. Within the ten-year period, the United States Air Force reported 239 hazardous cargo incidents. It must be noted that not all of these incidents were hazardous material related. However, 75 percent of the incidents were the result of fuel spills. The next most frequent category was corrosives, explosives, caustics and acids combined. The third most frequent incident in the Air Force involved solvents. The cause of many of these incidents was the incorrect preparation of the cargo manifest, and not draining fuel tanks and engines. 
Journal of Aviation/A erospace Education \& Research, Vol. 12, No. 1 [2002], Art. 5

\section{HAZARDOUS MATERIAL TRAINING}

The problems presented in the background section of this paper can generally all be traced to a breakdown in training. If a company wants to avoid HAZMAT violations, education is their only option (Martin, 1999). Training is vital to ensuring the safe transport of HAZMAT, everyone that might be involved needs to understand and comply with the requirements (Warner \& Rooney, 1999). One major problem is that companies do not have sufficient trained personnel to handle all shifts. Another common FAA fine is for freight forwarders not certifying employee training (Sobie, 1999). Compounding the problem is that even if a company refuses to ship any hazardous cargo they must still keep their employees trained so they can identify mislabeled shipments (Sobie, 1999).

One of the contributing factors in the Valujet crash was that the airline did not accept hazardous shipments and their people were not familiar with the handling or identification of these items. "This means that those transportation providers trying to get out of the business can never completely escape the need for education" (Sobie, 1999, p. 35). The best way to comply with Title 49 regulations is to thoroughly train all workers that are involved in packing and or shipping of hazardous materials (Thomas, 2001). The NTSB report following the Valujet crash stated that neither Sabre-Tech nor Valujet had an employee-training course for hazardous material identification. Sabre-Tech appeared to rely on the previous experience of their workforce to identify HAZMAT ("Chemical Oxygen," 1997).

Most would agree that people involved in the transportation of HAZMAT should receive training. This training should cover the substances they handle and be at a level that equals their responsibilities. The training should include familiarization with applicable requirements, specific aspects of their individual job in relation to the dangerous items they will come in contact with, and safety aspects to include an emergency response ("Recommendations On," 1995). The shipper is responsible for identifying and labeling the contents of each hazardous shipment (Kole, 2001). Although it is vital to have everyone knowledgeable, the "experts say the responsibility over undeclared goods rests with shippers and that any new regulations will have to include new standards for education" (Forsyth, 1998, p. 47).

Most HAZMAT violations result from not knowing or not understanding the HAZMAT regulations (Martin, 1999).
United Airlines has devised a 50-question checklist to aid their people who accept hazardous substances for air shipment. United has individuals, called Dangerous Goods Specialists who receive extensive and annual recurrent training. United acknowledges there are not enough of these trained specialists to locate them everywhere HAZAT is accepted. Therefore, United also mans a dangerous goods hotline with these specialists to assist their agents who do not have the same level of training. The majority of hazardous materials flown on United aircraft come from their own Stores Department and is called company material (Kole, 2001).

\section{REQUIREMENTS}

The transportation of HAZMAT was first regulated in the United States in the last half of the 1800s. The Department of Transportation became the responsible agency for the safe transport of hazardous materials in 1966 . The regulations that govern the movement of HAZMAT are published in 49 Code of Federal Regulations Parts 100 through 189. Employee training is currently mandated for everyone who loads, unloads, prepares for shipment, prepares paperwork, or handles hazardous material by 49 CFR Part 172 (Bierlein, 1996).

Code of Federal Regulations, Title 49 (the federal hazardous materials transportation law) regulates the transportation of HAZMAT within the United States. Among other things, it requires the training of all HAZMAT employees. The training must be consistent, provide for testing of the material covered in the training and be documented for each employee receiving the training. Topics for the training are nearly identical to the Dangerous Goods Regulation. The only addition is that people who operate a motor vehicle must also receive driver training. Also specified is that all employees must be trained within ninety days of being hired or changing the nature of their job. Just like in the Dangerous Goods Regulation, employees must be tested on the training and periodically receive refresher training.

The International Air Transport Association (IATA) Dangerous Goods Regulation (2000) is updated annually and provides air carriers and shippers the technical data needed to comply with government regulations and airline industry standards. The information contained within the Dangerous Goods Regulations are based on Annex 18 to the Chicago Convention and the Technical Instructions for the Safe Transport of Dangerous Goods by Air ("Dangerous Goods," 2000, p. xi). The Dangerous Goods Regulations 
call the need for training "essential" for the safe transport of these materials. The training required by the Dangerous Goods Regulations range from familiarization to detailed training. The purpose of the Dangerous Goods Regulations are simply stated as "...to provide procedures for the shipper and the operator by which articles and substances with hazardous properties can be safely transported by air on all commercial air transport" ("Dangerous Goods," 2000, p. xi). The IATA Dangerous Goods Regulations states that it is

...applicable to: all airlines which are Members or Associate Members of IATA; all airlines which are a party to the IATA Multilateral Interline Traffic Agreement - Cargo; and all shippers and agents that offer consignments of dangerous goods to these operators. ("Dangerous Goods," 2000, p. 1)

Section 1.5 of the Dangerous Goods Regulations (2000) details the various training requirements for shippers and transporters. All individuals involved in the air shipment of dangerous goods must receive initial and recurring training. The recurring training must occur every 24 months. Although the Dangerous Goods Regulations (2000) specify that training must take place, the specifics on the type of training is purposefully vague. The Regulations only specify that the training must be "commensurate" with the individual's responsibilities. Further, the training must include three things. First, it must provide for a general familiarization with dangerous goods procedures. Second, employees must be provided "function specific" training. The function specific training must be detailed for the task the individual performs. Third, employees must receive safety training to include emergency response procedures. In addition to conducting the training, a record of the training must be kept along with a copy of the certificate issued which indicates that a test was satisfactorily completed at the end of the training ("Dangerous Goods," 2000).

Although specifics on training are not included in the Dangerous Goods Regulations (2000), the Regulations provide a Minimum Requirements for Training Matrix that lists eight classifications of employees (shippers, packers, flight crew, etc) and the aspects (limitations, classifications, packaging, etc) they must be familiar with. The Regulations also specify dangerous goods that because of their nature are forbidden on aircraft at all times and under all conditions. The Regulations also provide a detailed list of the nine different hazardous material classes and required packing groups. The classes are explosives (class 1), gases (class 2), flammable liquids (class 3 ), flammable solids (class 4), oxidizing substances and organic peroxide (class 5), toxic and infectious (class 6), radioactive material (class 7), corrosives (class 8) and miscellaneous (class 9). The three packing groups refer to great, medium, and low danger and relate to the various hazardous material classifications ("Dangerous Goods," 2000).

Although there are pre-packaged training modules and companies that sell HAZMAT training, it is the employer's responsibility to establish a training program for their employees, the DOT does not approve individual, group, or company classes. Even if a company pays an outside agency to train their employees, the HAZMAT employer must still certify the training and testing. It is even authorized for someone to train himself or herself, for example, if they are an owner-operator. The test that employees must take does not have to be written and may instead be a demonstration of skills learned ("Code Of," 1999). Although the 49 CFR specifies the nature of the training that must be accomplished, the important point that the 49 CFR makes is that the training only needs to be appropriate and effective for the type of function that the specific employee will perform. Therefore, there are an almost endless number of training approaches and specifics taught.

"According to 49 CFR Part 172.2, no person can offer or accept a HAZMAT for transportation by air unless those goods are properly classified, packaged, marked and labeled, and in condition for shipment per the regs" (Martin, 1999, p. 66). The HAZMAT regulations also apply to passengers on commercial aircraft (Martin, 1999).

"HAZMATs transported by air must be labeled to meet the requirements of Subpart E of Part 172.400 in 49 CFR to identify the material and as necessary, to give proper warnings about handling it" (Martin, 1999, p. 67). The requirement is for each hazardous package to have a hazardous label that specifies the hazardous contents. Several substances have more than one type of hazardous contents and must therefore, have separate labels for each different hazardous content within the package (Martin, 1999).

Employees are generally given training so they can recognize HAZMAT labels. A problem with this training is that the FAA estimates that one-half of all hazardous material incidents are caused by undeclared shipments (Forsyth, 1997). Unfortunately, “...it is nearly impossible 
to track improperly labeled dangerous goods shipments until something goes wrong" (Forsyth, 1997, p. 34). Therefore, regulators stress the importance of dangerous goods education and training programs for all employees.

Within the United States there are several agencies jurisdictionally involved in the area of hazardous materials. DOT only regulates the transportation of HAZMAT, the EPA has jurisdiction over the release of hazardous substances into the air or ground, and OSHA is responsible for the health and safety of workers involved with HAZMAT (Currie, 1999). In those rare circumstances where the DOT, OSHA, and EPA have not exercised their authority, the state and local governments can create regulations for the protection of their citizens (Currie, 1999).

International and United States Federal law mandates that the pilot in charge of the aircraft must be notified about any HAZMAT placed on their aircraft (Kole, 2001). As the person responsible for the safety of the aircraft, the pilot in charge has the authority to refuse dangerous goods on their aircraft (Rogers, 2001).

The regulations that govern civilian air transportation of dangerous goods to, from and through the US begin with the United States Department of Transportation (DOT). The US Code of Federal Regulations (CFR) is divided into 50 titles representing broad areas that are regulated by the federal government. Title 49 CFR relates to transportation. DOTs' Research and Special Programs Administration creates the regulations that govern dangerous goods transportation. All shipments of HAZMAT to, from and through the US must comply with all aspects of 49 CFR and other regulations (Martin, 1999).

The Federal Hazardous Materials Transportation Law, 49 CFR Parts 100-185 is the basic statute regulating the transportation of dangerous goods in the United States. Civilian law requires the training and certification of all dangerous goods employees. Air Force Joint Manual 24204 (1997) is the governing regulation for training and certification as a Air Force HAZMAT handler.

Air Force Joint Manual 24-204, titled Preparing Hazardous Materials for Military Air Shipments (1997) provides instructions for preparing HAZMAT for air transportation aboard military aircraft. The regulation incorporates information contained in the Code of Federal Regulations, Title 49 (1999) and the International Civil Aviation Technical Instruction. Attachment 25 to Air Force Joint Manual 24-204 (1997) is titled Hazardous Materials
Initial and Refresher Training. The attachment explains that individuals are assigned to one of four different classifications based on the work performed. Further, individuals are trained based on the function performed with all individuals receiving the basic, or first level of training. Individuals assigned to any of the three higher level receive more detailed training based on the functions they perform.

\section{CONTINUED NEED FOR HAZARDOUS MATERIAL TRANSPORTATION}

Since the Valujet crash, many companies have had to rethink their hazardous material policies. Since the Valujet crash, Continental Airlines Cargo will only accept four of the nine dangerous goods classifications (Sobie, 1999). Not using air shipments for dangerous goods may not be option for some substances. Some items require speed of delivery because they are exceptionally time- and temperaturesensitive. Some companies in the agricultural, health, and chemical sectors must ship and receive biotech products within very limited time windows (Hong, 1993). Many of these shipments involve living cells that must be kept frozen with dry ice. To comply with safety requirements, the shipments are made in special containers that must be properly labeled as HAZMAT (Hong, 1993). Faced with fewer companies willing to handle HAZMAT, higher prices, and increased FAA oversight, many worry that more shippers will try to hide or mislabel dangerous goods tendered for shipment (Sobie, 1999).

Even companies that specialize in air cargo shipments don't have a large volume of dangerous goods shipments. FedEx reports HAZMAT shipments account for less than one-half of one percent of their volume and UPS estimates hazardous shipments are-less than one-tenth of one percent of their business (Sobie, 1999).

\section{PROCEDURES}

Civilian and military hazardous material training are different, yet both systems are designed to accomplish the safe transportation of HAZMAT. Since the training is different, and errors are still present, one must logically question if the effectiveness of one or the other method of training is superior. Therefore, the purpose of this study was to determine if the knowledge level of the civilian or military HAZMAT specialist was significantly different.

This research tested individuals from two separate populations. The first was the trained and certified dangerous goods air cargo handlers employed by 16 various civilian air carrier and freight forwarder agencies located 
within San Antonio, Austin, and Houston, Texas. The second was those military individuals performing HAZMAT duties at military installations located in the southwest region of the US. Therefore, the individuals tested within this research consisted of approximately 100 civilian dangerous goods employees and 100 military HAZMAT specialists.

This research utilized an achievement test in the form of surveys to collect data pertinent to the research hypotheses. Specifically, the survey (see Appendix A) included proficiency test measurements in the areas of generalized knowledge of the inspection, identification, marking and labeling, and compatibility procedures of hazardous materials required for certification by each population group. Also, the achievement test measured the general knowledge of recurring or follow-up training requirements following initial training in HAZMAT or dangerous goods. The test was created to be simple and generic so each target population could answer to the best of their own knowledge, without reference to the Hazardous Materials Regulations (HMR).

Questions 1 and 2 on the achievement test asked the respondent to describe their current employment position and length of employment. Question 3 asked the respondent to acknowledge if they have ever been trained in both civilian and military HAZMAT or dangerous goods handling. Questions 4 through 11 asked the respondent to acknowledge generalized knowledge of the inspection, identification, marking and labeling, compatibility, and recurring or follow-up training requirements of HAZMAT or dangerous goods handling. Each survey question had three possible responses of which only one was correct. The incorrect answers were combined into one wrong category for tabulation purposes.

As the data were nominal, the chi-square was seen as the correct test of statistical significance. The chi-square compared the civilian population to the military population using the percent of correct and incorrect responses.

The survey (see Appendix A) was hand-delivered or mailed to the civilian and military populations using a predetermined list of employers who had certified hazardous cargo employees. The authors conducted a telephone or personal interview with a shift supervisor to get permission to distribute the tests and determine the number of employees that were HAZMAT or dangerous goods trained and certified at each location. Each respective employer made the determination of how many achievement tests were required for his or her individual organization. Only trained and certified HAZMAT or dangerous goods employees received the achievement test. The supervisor then distributed the surveys. A self-addressed stamped envelope was included with a cover letter. Upon completion, each respondent placed their completed test in the envelope and mailed it to the authors.

Each employer received 20 percent more cover letters, achievement tests, and self-addressed stamped envelopes than they had employees. This was done to ensure a followup was accomplished within two weeks of the initial distribution. Due to the nature of the test, the authors assured anonymity to all companies and respondents. Two weeks after the initial distribution of the achievement tests supervisors were telephonically prompted to ask their employees if any surveys had been lost or not completed, and again offer the achievement tests to their employees who had not yet responded.

\section{RESULTS}

One hundred surveys were mailed to civilian dangerous goods employees and 100 surveys were mailed to military HAZMAT specialists. The authors received back 81 usable civilian surveys for an effective response rate of 81 percent. The authors also received back 91 usable military surveys for an effective response rate of 91 percent. Therefore, the overall response rate for this research was 86 percent. Because there was an unequal number of military and civilian respondents, all statistical comparisons were normalized through the use of percentages.

Question 4 on the achievement test asked the respondents to identify the steps required to properly identify a hazardous substance for air shipment. To answer correctly the respondents had to know that the hazardous material must first be identified (recognized) in the Hazardous Substance Table and the quantity must equal or exceed the Reportable Quantity located in the Hazardous Substance Table. 
Table 1

Comparison of Question 4 Results

\begin{tabular}{|c|c|c|c|}
\hline Categories & Number responding & Number correct & Percentage correct \\
\hline Civilian & 81 & 69 & 85.2 \\
\hline Military & 91 & 76 & 83.5 \\
\hline
\end{tabular}

The data in Table 1 resulted in a chi-square value of 0.209762 . With one degree of freedom, the chi-square value equated to a 35.3 percent confidence level that the data were different. Therefore, there was no statistical difference between the percentage of correct responses by the military and civilian participants.

Question 5 of the achievement test asked the respondent to accurately identify the form used to certify or document hazardous materials or dangerous goods for air shipment. To answer correctly, the respondents had to know that the Shippers Declaration for Dangerous Goods is the proper document to certify dangerous goods for air shipment. One hundred percent of both groups answered this question correctly.
Question 6 of the achievement test asked the respondent to accurately identify the regulation or regulations used for marking, labeling, and identifying HAZMAT or dangerous goods for air shipment. Again, 100 percent of both groups answered this question correctly.

Question 8 of the achievement test asked the respondent to accurately identify the required markings for non-bulk packaged cargo being shipped by air transportation if the item were a hazardous substance. To answer correctly the respondents had to know that an Identification (ID/UN) Number and proper shipping name was required on the dangerous good.

Table 2

\section{Comparison of Question 8 Results}

\begin{tabular}{|c|c|c|c|}
\hline Categories & Number responding & Number correct & Percentage correct \\
\hline Civilian & 81 & 78 & 96.3 \\
\hline Military & 91 & 89 & 97.8 \\
\hline
\end{tabular}

The data in Table 2 resulted in a chi-square value of 0.011592 . With one degree of freedom the chi-square value equated to an 8.574 percent confidence level that the data were different. Therefore, there was no statistical difference in the way military and civilian personnel responded to this question.

Question 9 on the achievement test asked the respondent to accurately identify which labels display the hazard class for HAZMAT or dangerous goods markings for cargo being shipped by air transportation. To answer correctly the respondents had to know that the Primary and Subsidiary labels must be affixed with the hazard class of the dangerous good being shipped. 
Table 3

Comparison of Question 9 Results

\begin{tabular}{|c|c|c|c|}
\hline Categories & Number responding & Number correct & Percentage correct \\
\hline Civilian & $\mathbf{8 1}$ & 67 & 82.7 \\
\hline Military & 91 & 75 & 82.4 \\
\hline
\end{tabular}

The data in Table 3 resulted in a chi-square value of 0.000545 . With one degree of freédom the chi-square value equated to a 1.86 percent confidence level that the data were different. Therefore, there was no difference between military and civilian knowledge.

Question 10 on the achievement test asked the respondent to accurately identify which table is used to determine if HAZMAT or dangerous goods shipped by air transportation may be stowed next to each other. To answer correctly the respondents had to know that the Compatibility/Segregation Table is used to determine if a dangerous good shipped by air transportation may be stowed next to another dangerous good.

Table 4

Comparison of Question 10 Results

\begin{tabular}{|c|c|c|c|}
\hline Categories & Number responding & Number correct & Percentage correct \\
\hline Civilian & 81 & 79 & 97.5 \\
\hline Military & 91 & 88 & 96.7 \\
\hline
\end{tabular}

The data in Table 4 resulted in a chi-square value of $\mathbf{0 . 2 0 0 5 5 8}$. With one degree of freedom the chi-square value equated to a 34.57 percent confidence level that the data were different. Therefore, there was no difference in the knowledge level of civilian and military personnel.

Question 11 on the achievement test asked the respondent to accurately acknowledge if a requirement exists for recurring training following initial HAZMAT or dangerous goods certification. One hundred percent of both groups answered this question correctly indicating no difference between the two groups.

Question 11 on the achievement test also asked the respondent to accurately identify what the frequency of recurring training is after initial certification.

\section{Table 5}

\section{Comparison of Question 11 Results}

\begin{tabular}{|c|c|c|c|}
\hline Categories & Number responding & Number correct & Percentage correct \\
\hline Civilian & 81 & 80 & 98.8 \\
\hline Military & 91 & 88 & 96.7 \\
\hline
\end{tabular}


The data in Table 5 resulted in a chi-square value of 1.38197. With one degree of freedom the chi-square value equated to a 76.02 percent confidence level that the data were different. Therefore there was no statistical difference between the two groups. In addition, it was determined that one civilian and two military respondents incorrectly identified the frequency of recurring training as a 12-month rotating cycle. These individuals were further identified as employees with less than 12 months experience as dangerous goods handlers. In other words, they had not been employed long enough to require accomplishing recurring training. One military respondent was also identified as having between 12 and 24 months as a dangerous goods handler. It is not clear if the individual had been employed long enough to require recurring training. Therefore, 100 percent of the military and civilians who would have been subject to recurrent training knew the correct answer.

Available demographic data enabled the further classification of respondent data. While tabulating the numbers, the researchers noted a large variation between categories of civilian respondents in relation to their type of employment. Achievement test Question 1 asked respondents to best describe their employment condition. Possible choices included military HAZMAT handler, civilian dangerous goods handler not employed by an airline, and civilian dangerous goods handler employed by an airline. Achievement test Question 4 asked the respondent to correctly recognize the steps required to properly identify a hazardous substance for air shipment. Responses from these questions were combined to determine if there was a statistical difference based on the type of civilian employment.

Table 6

Comparison of Question 4 Based on Type of Civilian Employment

\begin{tabular}{|c|c|c|c|}
\hline Categories & Number responding & Number correct & Percentage correct \\
\hline Civilian airline & 38 & 36 & 94.7 \\
\hline Civilian non-airline & 43 & 33 & 76.7 \\
\hline
\end{tabular}

The data in Table 6 resulted in a chi-square value of 18.1298. With one degree of freedom the chi-square value equated to a greater than 99.99 percent confidence level that the data were different. For the most part, dangerous goods cargo is delivered to the carrier (airline) by a certified shipper or freight forwarder. Therefore, the majority of the dangerous goods arrive with all the special handling procedures (i.e., documentation, certification, marking and labeling) having been complied with. It is possible the differences resulted because the civilians employed by the airlines are less frequently required to accomplish the identification and certification process. They may act more like a quality control to the process rather than actually performing the certification themselves. Therefore, the frequency with which dangerous goods handlers not employed by an airline receive and certify dangerous goods gave them a slight advantage over dangerous goods handlers employed by an airline.

Using civilian demographic data from Question 1, the researchers noticed a large variation between civilians employed and not employed by an airline concerning labeling information. Question 9 asked respondents to correctly acknowledge which labels required the hazard class of the dangerous goods being shipped by air transportation.

Table 7

Comparison of Question 9 Based on Type of Civilian Emplovment

\begin{tabular}{|c|c|c|c|}
\hline Categories & Number responding & Number correct & Percentage correct \\
\hline Civilian airline & 38 & 35 & 92.1 \\
\hline Civilian non-airline & 43 & 32 & 74.4 \\
\hline
\end{tabular}


The data in Table 7 resulted in a chi-square value of 16.4488. With one degree of freedom the chi-square value equated to a greater than 99.99 percent confidence level that the data were different. Therefore, those respondents not employed by an airline better understood the labeling information. Normally, dangerous goods cargo is delivered to the carrier (airline) by a certified shipper or freight forwarder. Therefore, the majority of the dangerous goods arrive with packaging and certification, to include label marking, already complied with. Civilians employed by the airline are less frequently required to accomplish the marking and certification process. They act more as a quality control to the process rather than actually performing the certification themselves. Therefore, the frequency with which dangerous goods handlers not employed by an airline receive and certify dangerous goods give them a slight advantage of repetition over dangerous goods handlers employed by an airline.

While tabulating the data, the researchers also noted a difference between military and civilian respondents based on their experience levels. Achievement test Question 2 asked respondents their length of employment as a certified dangerous goods handler. Possible answers included less than 12 months, 12 to 24 months and greater than 24 months. Achievement test Question 4 asked the respondent to correctly recognize the steps required to properly identify a hazardous substance for air shipment.

Table 8

Comparison of Question 4 Based on Less than 12 Months of Employment

\begin{tabular}{|c|c|c|c|}
\hline Categories & Number responding & Number correct & Percentage correct \\
\hline Civilian & 17 & 13. & 76.5 \\
\hline Military & 36 & 33 & 91.7 \\
\hline
\end{tabular}

The data in Table 8 resulted in a chi-square value of 12.8516. With one degree of freedom the chi-square value equated to a 99.97 percent confidence level that the data were different. Therefore, the military personnel with limited experience better understood the steps required to properly identify a hazardous substance for air shipment. Following initial dangerous goods certification, the majority of military HAZMAT handlers proceed directly to an operational unit and begin accomplishing these duties with complete authorization and little or no supervision. Conversely, civilian dangerous goods handlers enter employment at the entry-level position and frequently have limited authority to accomplish certification procedures until after a lengthy over-the-shoulder review from a supervisor. For this reason military HAZMAT handlers with less than 12 months employment will accomplish the actual certification process more frequently and with limited supervisory involvement more often than civilian dangerous goods employees do with less than 12 months employment. This affords the military population with less than 12 months of employment to have a slight advantage over the civilian population.

Table 9

Comparison of Question 4 Based on Greater than 24 Months of Employment

\begin{tabular}{|c|c|c|c|}
\hline Categories & Number responding & Number correct & Percentage correct \\
\hline Civilian & 40 & 37 & 92.5 \\
\hline Military & 32 & 24 & 75.0 \\
\hline
\end{tabular}


The data in Table 9 resulted in a chi-square value of 16.333. With one degree of freedom the chi-square value equated to a greater than 99.99 percent confidence level that the data were different. Therefore, civilians with more than 24 months of experience better understood the steps required to properly identify hazardous materials for air shipment. As civilian dangerous goods handlers gain experience their proficiency increases. To a certain degree, the same dynamics occur with the military HAZMAT handler. However, military HAZMAT handlers have a greater potential to get assigned additional duties once their experience increases, or they get promoted. These additional duties do not normally include continuing to maintain proficiency as a HAZMAT handler. The supervisory, non-technical role comes quicker in the military environment than in the civilian environment. For these reasons military respondents with greater than 24 months experience as a HAZMAT handler scored poorer on achievement test Question 7 than civilian respondents with the same amount of experience.

Using the same demographic results with respect to length of employment, achievement test Question 7 asked what specific marking is required on dangerous cargo being shipped by air transportation.

Table 10

Comparison of Question 7 Based on Less than 12 Months of Employment

\begin{tabular}{|c|c|c|c|}
\hline Categories & Number responding & Number correct & Percentage correct \\
\hline Civilian & 17 & 14 & 82.4 \\
\hline Military & 36 & 35 & 97.2 \\
\hline
\end{tabular}

The data in Table 10 resulted in a chi-square value of 15.1037. With one degree of freedom the chi-square value equated to a 99.99 percent confidence level that the data were different. Again, there was a difference in the knowledge level of military and civilian personnel with limited experience with the military personnel having the higher percentage of correct answers.

Following initial dangerous goods certification, the majority of military HAZMAT handlers proceed directly to an operational unit and begin accomplishing these duties with complete authorization and little or no supervision. Conversely, civilian dangerous goods handlers enter employment at the entry-level position and frequently have limited authority to accomplish certification procedures until after a lengthy over-the-shoulder review from a supervisor. For this reason HAZMAT handlers with less than 12 months employment will accomplish the actual certification process more frequently and with limited supervisory involvement more often than civilian dangerous goods employees do with less than 12 months employment. This affords the military population with less than 12 months of employment to have a slight advantage over the civilian population.

\section{SUMMARY}

It is not uncommon to have civilian airline passengers occupy seats and have dangerous goods secured below in the cargo hold. It is also not unusual to have military passengers occupy seats adjacent to secured HAZMAT cargo where space permits (not all types of military aircraft have separate configuration levels to shield passengers from cargo). One of the most important safety features between these passengers and a hazardous material caused disaster is the training of the hazardous material specialists who classified, packaged, labeled, and loaded the hazardous cargo on the aircraft. Although this was a preliminary study, conducted in a single geographical location, the results are clear. The nature of the training the military and civilians receive prior to being certified is different. However, the data indicate that both methods are effective. The only differences found occurred when the length of time an individual had been doing the job was taken into consideration and when the nature of the civilian job performed was considered. 
Bruce A. Rothwell earned his doctorate of Public Administration from the University of Alabama. He is a retired US Air Force logistician and is currently an Assistant Professor with Embry-Riddle Aeronautical University.

Wayne Harsha earned his doctorate in Education from the University of Montana. He is a retired US Air Force pilot and is currently an Associate Professor with Embry-Riddle Aeronautical University.

Theodore Clever earned a Master of Aeronautical Science degree from Embry-Riddle Aeronautical University. He is a retired US Air Force load master instrucţor who also handled hazardous material and is currently employed by a commercial airline company. 


\section{REFERENCES}

Air Force Joint Manual 24-204. (1997). Preparing hazardous materials for military air shipments. Washington, DC: Headquarters United States Air Force.

After smoke detected in cargo compartment crew lands DC-10, then fire destroys aircraft. (1998). Flight Safety Foundation Accident Prevention, 55, 1-19.

Beckham, D. J. (1999). Implications for healthcare. Health Forum Journal, 42, 51-53.

Bierlein, L. W. (1996). Transportation regulations applicable to environmentally hazardous substances. Journal of Environmental Law \& Practice, 3, 30-36.

Chemical oxygen generator activates in cargo compartment of DC-9, causes intense fire and results in collision with terrain. (1997). Flight Safety Foundation Accident Prevention, 54, 1-23.

Chipkevich, R. J. (1996). Safeguarding against hazardous cargo aboard aircraft presents a variety of challenges. International Civil Aviation Organization Journal, 51, 20-23

Code of Federal Regulations. (1999). Title 49, Subpart H. Training requirements under the hazardous materials regulations. Washington, DC: United States Government Printing Office.

Currie, J. V. (1999). Defining the " $T$ " in DOT. Logistics Management and Distribution Report, 38, 38-39.

Dangerous Goods Regulations (40 $\mathrm{ed}$.). (2000). Montreal, Canada: International Air Transport Association.

Forsyth, G. (1997). The new hazards of air shipping. Air Cargo World, 26-34.

Forsyth, G. (1998). Hazardous ignorance. Is danger in the air? Air Cargo World, 42-49.

Gethin, S. (1996). The growing dangers of hazardous cargo. Air Cargo World, 33-40.

Hong, M. (1993). Air carriers help firms race biotechnological clock. AirCommerce, 1-3.

Kole, C. (2001). Preparation and processing of hazardous materials. Safetyliner, 4-7.

Martin, L. L. (1999). HAZMAT do's and don'ts. Business and Commercial Aviation, 66-67.

Mokhiber, R. (1999). Valujet crash aftermath. Multinational Monitor, $20,30$.

Recommendations on the transport of dangerous goods ( $9^{\text {th }}$ ed). (1995). New York: United Nations.

Rocket fuel cargo may have caused SAA 747 death crash. (2000). Flight International, 22.

Rogers, M. (2001). Dangerous goods. Safetyliner, 11, 8-11.

Sobie, B. (1999). Cargo nobody wants. Air Cargo World, 27-35.

Thomas, P. (2001). Safe transport of HazMats. Professional Safety, 46, 31-32.

Trautveller, C. (2000). Learning the ins and outs of transporting hazmat. Aviation International, 88.

Voge, V. M., \& Tolan, G. (1993). Hazardous materials incidents in military aircraft. Aviation Space \& Environmental Medicine, 64, 658-661.

Warner, K., \& Rooney, K. (1997). ICAO technical instructions provide a complete system for the transport of dangerous goods by air. International Civil Aviation Organization Journal, 52, 23-29. 


\section{APPENDIX A SURVEY}

\section{INSTRUCTIONS: Indicate your}

1. Which response best describes your current employment condition?
a. Military HAZMAT handler
b. Civilian Dangerous Goods handler but not employed by an airline
c. Civilian Dangerous Goods handler employed by an airline

2. Which statement best describes the length of time you have been employed as a HAZMAT or dangerous goods handler?
a. Less than $\mathbf{1 2}$ months
b. 12 to 24 months
c. greater than $\mathbf{2 4}$ months

3. Have you ever received both military and civilian HAZMAT or Dangerous Goods training?
a. Yes
b. No

4. What are the steps required to properly identify a hazardous substance for air shipment?

a. The item must be identified in the Hazardous Substance Table; and, must equal or exceed the Reportable Quantity located in the Hazardous Substance Table

b. The item must be identified in the Hazardous Substance Table and the Hazardous Materials Table

c. The item must include a Class 1 Explosive or Class 4 Flammable Solid

5. What form is used to certify or document hazardous materials or dangerous goods for air shipment?
a. Shippers Declaration
b. Dangerous Goods Receipt
c. Hazardous Materials Receipt

6. Which response best identifies the regulation(s) used for marking, labeling, and certifying

HAZMAT or dangerous goods for air shipment?
a. Title 49 CFR, IATA, and ICAO
b. Title $40 \mathrm{CFR}$ and IOPA
c. NATA

response by circling the correct answer.

7. What marking is required on cargo being shipped by air transportation if the item is a hazardous substance?
a. Reportable Quantity (RQ)
b. Indicated Quantity (IQ)
c. No marking required

8. Unless excepted, each person who offers a HAZMAT or dangerous good in a non-bulk packaging for air transportation shall mark the package with?
a. Hazard Class and Packaging Group
b. Hazard Class and Identification (ID/UN) Number
c. Proper Shipping Name and Identification (ID/UN) Number

9. With reference to labeling requirements for HAZMAT or dangerous goods for air transportation shipment, the hazard class will be displayed on the lower corner of which label(s)?
a. Primary and Subsidiary Labels
b. Primary Hazard Label
c. Subsidiary Label

10. The table used to determine if HAZMAT or dangerous goods shipped by air transportation may be stowed next to each other is?
a. Compatibility/Segregation Table
b. Hazardous Materials Table
c. Reportable Quantity Table

11. Is there a requirement for recurring training following initial HAZMAT or dangerous goods certification for air transportation? If so, what is the frequency?
a. Yes, recurrent training is required every 24 months following initial certification.
b. Yes, recurrent training is required every $\mathbf{1 2}$ months following initial certification.
c. No, recurrent training is not required following initial certification.


Journal of Aviation/Aerospace Education \& Research, Vol. 12, No. 1 [2002], Art. 5 